\title{
Feasibility of Single-Incision Laparoscopic Appendectomy in Pregnant Women
}

\author{
Myoung Won Son, Geum Jong Song, Moon Soo Lee \\ Department of Surgery, Soonchunhyang University Cheonan Hospital, Cheonan, Korea
}

\begin{abstract}
Objective: Owing to advances in laparoscopic technique and equipment, a single-port laparoscopic surgery has been applied in various fields of surgery. However, the application of a single-port laparoscopic surgery for pregnant women has been rarely reported. The aim of this study was to emphasize the feasibility of single-port laparoscopic appendectomy in pregnant women.

Methods: In seven pregnant women who underwent abdominal ultrasonography and physical examination, surgery was performed under the diagnosis of acute appendicitis. In all the patients, single-port laparoscopic appendectomy was performed in the same way. The laparoscopic surgical devices used during surgery were same as those in conventional laparoscopic appendectomy. Results: Age ranged from 25 to 33 years (mean, 29.7 years), gestational age ranged from 7 weeks 3 days to 17 weeks 6 days (mean gestational age, 14 weeks 3 days). The mean operation time was 19 minutes (range, 16-22 minutes). No surgical related complications and any issues occurred.

Conclusion: Single-port laparoscopic appendectomy for pregnant women is considered one of the treatment methods.
\end{abstract}

Keywords: Appendectomy; Pregnancy; Laparoscopy

\section{INTRODUCTION}

The most common disease that require surgery in pregnancy is appendicitis [1]. Nowadays, laparoscopic appendectomy is the treatment of choice for acute appendicitis [2]. Laparoscopic surgery has the advantage of decreased pain, shorter recovery time and length of hospital stay, fewer adhesions, and improved cosmetics [3-6]. Despite the many advantages, laparoscopic appendectomy for pregnant women has caused a major controversy because pneumoperitoneum using carbon dioxide could decrease the blood flow into the uterus and increase the risk of fetal acidemia [7].

In several studies, no statistical differences in maternal and fetal outcomes were found between laparotomy and laparoscopy in pregnancy [8-10]. Furthermore, the aim of our study was to emphasize that single-port laparoscopic appendectomy is a safe and feasible procedure for the treatment of acute appendicitis during pregnancy.

\section{MATERIALS AND METHODS}

From January 30, 2013 to December 18, 2013, seven pregnant women underwent single-port laparoscopic appendectomy by a single surgeon at the Soonchunhyang University Cheonan Hospital. This study was approved by the institutional review board of Soonchunhyang University Cheonan Hospital (IRB approval no., 18-397). And the written informed consent was obtained. Five of the seven pregnant patients visited the emergency department, and two were admitted through the outpatient clinic. All the patients represented clinical symptoms of acute appendicitis such as right lower abdominal pain. Among the seven pregnant patients who were suspected of having acute appendicitis, six had a confirmed acute appendicitis on appendix ultrasonography and one was diagnosed on the basis of the result of physical examination and laboratory tests using a blood sample.

In all the patients, single-port laparoscopic appendectomy was performed in the same way and the laparoscopic surgical devices
Correspondence to: Moon Soo Lee

Department of Surgery, Soonchunhyang University Cheonan Hospital, 31 Suncheonhyang 6-gil, Dongnam-gu, Cheonan 31151, Korea

Tel: +82-41-570-3635, Fax: +82-41-571-0129, E-mail: msslee@schmc.ac.kr

Received: Mar. 23, 2018 / Accepted after revision: May 10, 2018
(C) 2018 Soonchunhyang Medical Research Institute

This is an Open Access article distributed under the terms of the Creative Commons Attribution Non-Commercial License (http://creativecommons.org/licenses/by-nc/4.0/). 
used during surgery were same as those in conventional laparoscopic appendectomy. Under general anesthesia, a 2.5-cm incision was made through the umbilicus, and then Octo-Port (Dalim, Seoul, Korea) was inserted via the umbilical wound (Fig. 1). Pneumoperitoneum was made with $10 \mathrm{~mm} \mathrm{Hg}$ of pressure by using a carbon dioxide injection. The appendix was caught and retracted by using Babcock forceps, and the mesoappendix was cauterized with Marseal bipolar (KLS Martin, Tuttlingen, Germany). After the base of the appendix was knotted with LapLoop (Ethicon, Somerville, NJ, USA), the appendix was ligated (Fig. 2). The appendix was removed through the umbilical port without using LapBag and any drain. The umbilical port site was closed with 2-0

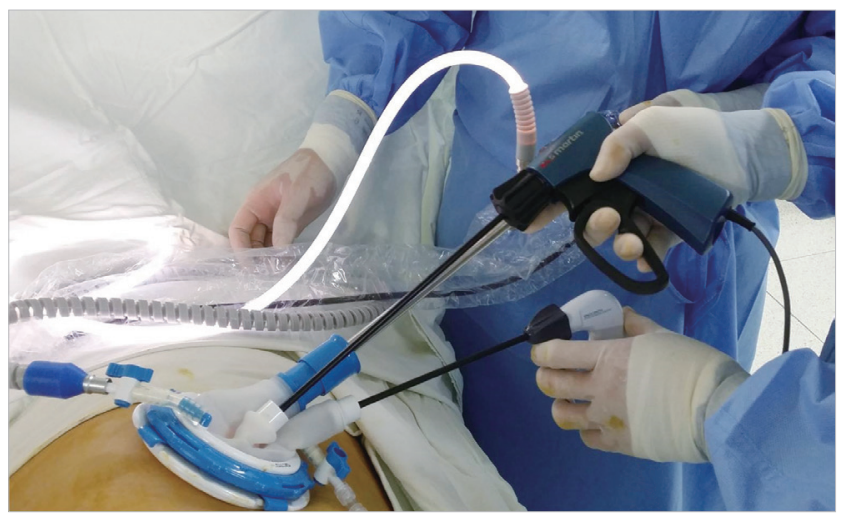

Fig. 1. The position of the hands of the operator and assistant during the procedure are shown. polysorb (Covidien, Mansfield, MA, USA), and the skin was closed with interrupted 3-0 nylon (Fig. 3).

\section{RESULTS}

The mean age of the pregnant patients was 29.7 years (range, 25-33 years), and the mean gestational period was 14 weeks 3 days (range, 7 weeks 3 days to 17 weeks 6 days). The mean operation time was 19 minutes (range, 16-22 minutes), the port insertion time was 4 minutes (range, $2-5$ minutes), the main procedure time was 9 minutes (range, 5-13 minutes), and wound closure time was 6 minutes (range, 3-8 minutes). The mean postoperative hospital

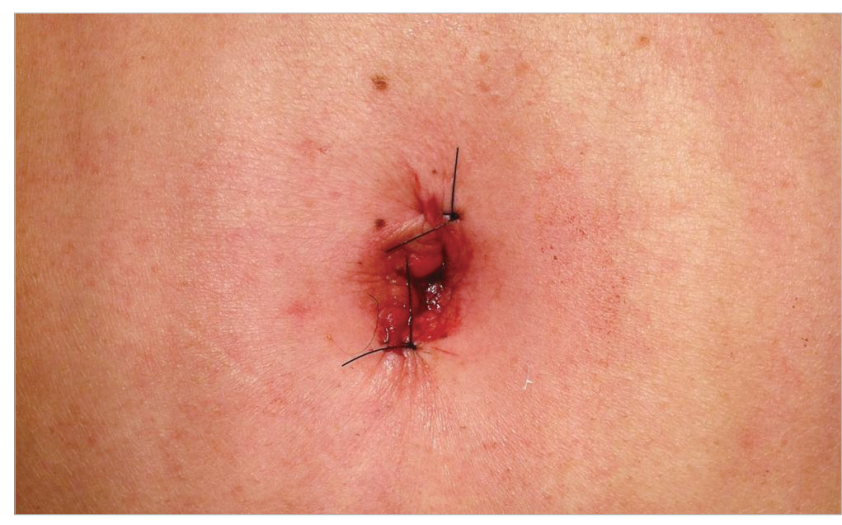

Fig. 3. Immediate postoperative wound. The incision site is only on the umbilicus.
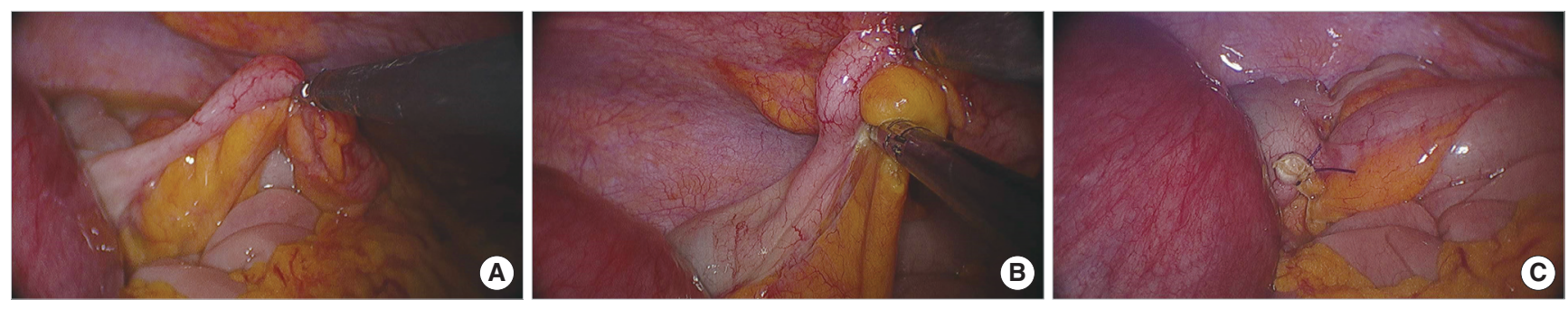

Fig. 2. (A) The appendix is tractioned with Babcock forceps. (B) The mesoappendix is transected with Marseal bipolar (KLS Martin, Tuttlingen, Germany). (C) Post-appendectomy finding. The appendix stump is cut neatly.

Table 1. Details of the patients included in this study

\begin{tabular}{|c|c|c|c|c|c|c|c|c|}
\hline Characteristic & Case 1 & Case 2 & Case 3 & Case 4 & Case 5 & Case 6 & Case 7 & Mean \\
\hline Age (yr) & 25 & 32 & 30 & 26 & 33 & 30 & 32 & 29.7 \\
\hline Gestational age (wk) & 17.5 & 15 & 7.3 & 15.2 & 15 & 13 & 17.6 & 14.3 \\
\hline Port insertion time (min) & 4 & 5 & 5 & 5 & 4 & 3 & 2 & 4 \\
\hline Main procedure time (min) & 5 & 8 & 11 & 8 & 10 & 8 & 13 & 9 \\
\hline Wound closure time (min) & 7 & 7 & 6 & 8 & 5 & 6 & 3 & 6 \\
\hline Total operation time (min) & 16 & 20 & 22 & 21 & 19 & 17 & 18 & 19 \\
\hline Hospital stay (day) & 6 & 3 & 7 & 6 & 4 & 3 & 4 & 4.7 \\
\hline
\end{tabular}


stay was 4.7 days (range, 3-7 days), but two patients were transferred to the obstetrics department for observation after surgery; our research included these periods. This is the reason for the longer hospital stay in our study than in other studies (Table 1).

In all the patients, a pathological report confirmed the acute suppurative or exudative appendicitis. No surgery-related complications and issues occurred, except for one case of preterm labor, which was cured by conservative treatment. All the seven pregnant patients gave birth to healthy babies, and five babies were delivered by cesarean section.

\section{DISCUSSION}

To perform a surgical intervention under general endotracheal anesthesia in pregnancy imposes a heavy burden on the surgeon. This is because all surgical procedures performed during pregnancy, including laparoscopy, has been shown to increase the risk of fetal loss $[11,12]$. Laparoscopic appendectomy has been accepted as a treatment option for acute appendicitis $[3,13,14]$. Nonetheless, still many arguments oppose laparoscopic appendectomy in pregnancy. Trocar positioning or movement of devices may injure the enlarged uterus. Moreover, pneumoperitoneum during laparoscopy increases intra-abdominal pressure and may cause hypoperfusion. This can lead to fetal acidosis or preterm delivery $[7,13,15]$.

However, not only laparoscopic appendectomy but also open appendectomy can cause problems for the mother and fetus. $\mathrm{Pa}$ tients who undergo open appendectomy require greater volumes of analgesics because of the large incision. Postoperative pain in pregnant women is a high risk of uterine contraction, preterm labor, and abortion [16-18].

In our study, the mean operative time was 19 minutes, but the main procedure was performed in 9 minutes on average. Namely, pneumoperitoneum only lasted for 9 minutes. Moreover, the carbon dioxide pressure was maintained at $10 \mathrm{~mm} \mathrm{Hg}$. Two patients had a previous cesarean section scar, but we successfully performed a single-port laparoscopic surgery for acute appendicitis. Therefore, barring a few drawbacks, single-port laparoscopic appendectomy has several advantages in pregnancy.

Surgeries performed during the first trimester are more likely to lead to abortion, whereas the risk of preterm labor increases during the third trimester $[7,11,19,20]$. In our study, all the seven pregnant women's gestational ages ranged from 7 weeks 3 days to 17 weeks 6 days.
The limitations of our study include the absence of cases during the third trimester and the small sample size, with only seven patients. However, to the best of our knowledge, our study is probably the first to report about single-incision laparoscopic appendectomy in pregnancy.

In conclusion, single-port laparoscopic appendectomy for pregnant patients is a safe and feasible procedure, and can be considered an alternative to open appendectomy or conventional laparoscopic appendectomy.

\section{REFERENCES}

1. Mazze RI, Kallen B. Appendectomy during pregnancy: a Swedish registry study of 778 cases. Obstet Gynecol 1991;77:835-40.

2. Horvath P, Lange J, Bachmann R, Struller F, Konigsrainer A, Zdichavsky M. Comparison of clinical outcome of laparoscopic versus open appendectomy for complicated appendicitis. Surg Endosc 2017;31:199-205.

3. Sauerland S, Jaschinski T, Neugebauer EA. Laparoscopic versus open surgery for suspected appendicitis. Cochrane Database Syst Rev 2010;(10):CD001546.

4. Guidelines Committee of the Society of American Gastrointestinal and Endoscopic Surgeons, Yumi H. Guidelines for diagnosis, treatment, and use of laparoscopy for surgical problems during pregnancy: this statement was reviewed and approved by the Board of Governors of the Society of American Gastrointestinal and Endoscopic Surgeons (SAGES), September 2007. It was prepared by the SAGES Guidelines Committee. Surg Endosc 2008;22:849-61.

5. Koh AR, Lee JH, Choi JS, Eom JM, Hong JH. Single-port laparoscopic appendectomy during pregnancy. Surg Laparosc Endosc Percutan Tech 2012;22:e83-6.

6. Donmez T, Hut A, Avaroglu H, Uzman S, Yildirim D, Ferahman S, et al. Two-port laparoscopic appendectomy assisted with needle grasper comparison with conventional laparoscopic appendectomy. Ann Surg Treat Res 2016;91:59-65.

7. Jeong JS, Ryu DH, Yun HY, Jeong EH, Choi JW, Jang LC. Laparoscopic appendectomy is a safe and beneficial procedure in pregnant women. Surg Laparosc Endosc Percutan Tech 2011;21:24-7.

8. Sadot E, Telem DA, Arora M, Butala P, Nguyen SQ, Divino CM. Laparoscopy: a safe approach to appendicitis during pregnancy. Surg Endosc 2010;24:383-9.

9. Carter JF, Soper DE. Operative laparoscopy in pregnancy. JSLS 2004;8:5760.

10. Oelsner G, Stockheim D, Soriano D, Goldenberg M, Seidman DS, Cohen $\mathrm{SB}$, et al. Pregnancy outcome after laparoscopy or laparotomy in pregnancy. J Am Assoc Gynecol Laparosc 2003;10:200-4.

11. Lemieux P, Rheaume P, Levesque I, Bujold E, Brochu G. Laparoscopic appendectomy in pregnant patients: a review of 45 cases. Surg Endosc 2009;23:1701-5.

12. Reedy MB, Kallen B, Kuehl TJ. Laparoscopy during pregnancy: a study of five fetal outcome parameters with use of the Swedish Health Registry. Am J Obstet Gynecol 1997;177:673-9.

13. Hannan MJ, Hoque MM, Begum LN. Laparoscopic appendectomy in pregnant women: experience in Chittagong, Bangladesh. World J Surg 2012;36:767-70. 
14. Kang BH, Yoon KC, Jung SW, Lee GR, Lee HS. Feasibility of single-incision laparoscopic appendectomy in a small hospital. Ann Surg Treat Res 2016;91:74-9.

15. Rizzo AG. Laparoscopic surgery in pregnancy: long-term follow-up. J Laparoendosc Adv Surg Tech A 2003;13:11-5.

16. Lee SY, Park YG, Chang IT. The comparative analysis between laparoscopic and open appendectomy. J Korean Surg Soc 2004;67:65-9.

17. Long KH, Bannon MP, Zietlow SP, Helgeson ER, Harmsen WS, Smith $\mathrm{CD}$, et al. A prospective randomized comparison of laparoscopic appendectomy with open appendectomy: clinical and economic analyses. Sur- gery 2001;129:390-400

18. Navarra G, Ascanelli S, Turini A, Carcoforo P, Tonini G, Pozza E. Laparoscopic appendectomy versus open appendectomy in suspected acute appendicitis in female patients. Ann Ital Chir 2002;73:59-63.

19. Society of American Gastrointestinal Endoscopic Surgeons (SAGES). Guidelines for laparoscopic surgery during pregnancy. Surg Endosc 1998; 12:189-90.

20. Cohen-Kerem R, Railton C, Oren D, Lishner M, Koren G. Pregnancy outcome following non-obstetric surgical intervention. Am J Surg 2005; 190:467-73. 